\title{
Manifestações patológicas em fachadas de construções históricas: estudo de caso da Igreja de Nossa Senhora do Carmo em São Luís - MA
}

\author{
Pathological manifestations on the facades of historic buildings: a case study of the Igreja de Nossa \\ Senhora do Carmo in São Luís - MA \\ Manifestaciones patológicas en las fachadas de edificios históricos: un estudio de caso de la Igreja \\ de Nossa Senhora do Carmo en São Luís - MA
}

Recebido: 16/01/2022 | Revisado: 21/01/2022 | Aceito: 21/01/2022 | Publicado: 23/01/2022

\author{
Luan da Silva Costa \\ ORCID: https://orcid.org/0000-0002-6191-301X \\ Universidade Federal do Maranhão, Brasil \\ E-mail: luan.silva@discente.ufma.br \\ Witson Andrade da Silva \\ ORCID: https://orcid.org/0000-0001-5155-7579 \\ Universidade Federal do Maranhão, Brasil \\ E-mail: eng.silva10@hotmail.com
}

\begin{abstract}
Resumo
Os monumentos históricos são obras importantes para a sociedade, pois guardam parte da história de lugares e pessoas de vários séculos, por isso, é importante que sejam devidamente preservados, para que essa história não se perca. Com isso, este trabalho tem o objetivo de identificar e analisar as manifestações patológicas encontradas em edifícios históricos, através do estudo de caso da fachada da Igreja de Nosssa Senhora do Carmo e propor as possíveis causas e terapias de restauro. Apesar de ter vários séculos de existência, notou-se que a fachada da igreja permanece bem conservada em relação aos demais imóveis da região, no entanto, foi possível encontrar algumas avarias. Foi possível detectá-las através de visitas ao local e de inspeções visuais e fotográficas, além de comparações com as bibliografias estudadas. Com isso, foi possível identificar e examinar as manifestações patológicas encontradas, sugerir alguns restauros, para que a fachada da igreja de Nossa Senhora do Carmo continue com um bom nível de preservação.
\end{abstract}

Palavras-chave: Manifestações patológicas; Monumentos históricos; Construção civil.

\begin{abstract}
The historical monuments are important works for the society, because they keep part of the history of places and people from several centuries, so it is important that they are properly preserved, so that this history is not lost. Thus, this work aims to identify and analyze the pathological manifestations found in historic buildings, through the case study of the facade of the Church of Our Lady of Carmel and propose possible causes and restoration therapies. Despite being several centuries old, it was noted that the church's facade remains well preserved in relation to other buildings in the region, however, it was possible to find some malfunctions. It was possible to detect them through site visits and visual and photographic inspections, as well as comparisons with the bibliographies studied. With this, it was possible to identify and examine the pathological manifestations found, and to suggest some restorations, so that the facade of the church of Nossa Senhora do Carmo continues with a good level of preservation.
\end{abstract}

Keywords: Pathological manifestations; Historic monuments; Civil construction.

\section{Resumen}

Los monumentos históricos son obras importantes para la sociedad, porque guardan parte de la historia de lugares y personas de varios siglos, por lo que es importante que se conserven adecuadamente, para que esta historia no se pierda. Con ello, este trabajo pretende identificar y analizar las manifestaciones patológicas encontradas en los edificios históricos, a través del estudio de caso de la fachada de la Iglesia de Nosssa Senhora do Carmo y proponer posibles causas y terapias de restauración. A pesar de tener varios siglos de existencia, se observó que la fachada de la iglesia se mantiene bien conservada en relación con otros edificios de la región, sin embargo, fue posible encontrar algunas fallas. Se han podido detectar a través de visitas al lugar y de inspecciones visuales y fotográficas, así como de comparaciones con las bibliografías estudiadas. Con esto, fue posible identificar y examinar las manifestaciones patológicas encontradas, para sugerir algunas restauraciones, de modo que la fachada de la iglesia de Nossa Senhora do Carmo continúe con un buen nivel de conservación.

Palabras clave: Manifestaciones patológicas; Monumentos históricos; Construcción civil. 


\section{Introdução}

Os edifícios históricos fazem parte da cultura dos antepassados, além do mais, constituem o patrimônio histórico da humanidade, com isso, é do interesse da sociedade manter essas construções em bom estado de conservação, garantindo assim que a tradição e cultura dos povos de diferentes lugares se mantenha intacta por muito tempo. Essas construções também são monumentos turísticos e arquitetônicos, o que é benéfico para a economia do local em que se encontram (Tavares, 2011).

Além da proteção da cultura que gira em torno dos edifícios históricos, também é importante conservação dos componentes estruturais, devendo haver manutenção e recuperação periódicas desses elementos, trazendo assim, segurança e garantindo a proteção do bem histórico e dos visitantes que passam por ali. Com isso, é importante conhecer e identificar as manifestações patológicas que afetam essas edificações, sobretudo em suas fachadas, no qual tem bastante relevância arquitetônica, turística e cultural (Tavares, 2011).

De acordo com Lersch (2003), a investigação das manifestações patológicas que acometem essas edificações, é essencial para o entendimento das possíveis causas e dos meios de deterioração, consequentemente, também é importante para a prevenção, restauração e diagnóstico correto.

Diante disso, pode-se perceber facilmente que os edifícios históricos sofrem mais com essas manifestações patológicas, pois é evidente que tiveram maior deterioração das intempéries ao longo do tempo, além do seu sistema construtivo ser menos preparado para elas em relação às construções atuais. Com isso, as fachadas dessas construções antigas geralmente são mais acometidas, no que diz respeito a estética, pelas patologias, o que remete à preservação da arquitetura e cultura local (Barbosa, 2017).

A capital do Maranhão, São Luís, é um exemplo de cidade com um patrimônio histórico extenso, com casarões, igrejas, ruas e monumentos construídos pelos portugueses no século XVII, com revestimentos de azulejos nas fachadas que faz com que o lugar seja um dos mais bonitos da capital maranhense. O Centro Histórico resistiu bem ao crescimento da cidade, com isso, é um dos pontos turísticos mais visitados, pois preserva bem a história e cultura do local (Iphan, s. d.).

Apesar de ter uma boa preservação, o Centro Histórico de São Luís possui monumentos que necessitam de atenção, que é o caso da Igreja de Nossa Senhora do Carmo, que alvo deste estudo. Neste trabalho, terá um levantamento e análise das manifestações patológicas predominantes na fachada desta edificação.

Diante disso, o objetivo deste estudo é identificar e analisar as manifestações patológicas encontradas em fachadas de edifícios históricos, além de propor possíveis causas e possíveis terapias para os problemas encontrados, e para isso, foi utilizada a Igreja de Nossa Senhora do Carmo em São Luís - MA como objeto de estudo.

\section{Referencial Teórico}

\section{O Centro Histórico e a Igreja de Nossa Senhora do Carmo}

O Centro Histórico da cidade de São Luís é um acervo com inúmeros monumentos e edificações que são consideradas Patrimônio Cultural Mundial pela Organização das Nações Unidas para a Educação, a Ciência e a Cultura (UNESCO), título no qual foi dado no ano de 1997. De acordo com o Iphan (s. d.), o Centro Histórico de São Luís possui por volta de mil construções históricas, erguidas durante os séculos XVII e XIX, com arquitetura portuguesa da época.

Segundo Corrêa (2001), mesmo com as eventualidades e contratempos da época, o Centro Histórico se manteve bem preservado, apesar do passar dos séculos que degradam significativamente construções antigas e a falta de manutenções periódicas no acevo, além da modernização da cidade com um todo.

Com a boa preservação do Centro Histórico, a Igreja de Nossa Senhora do Carmo também se manteve relativamente bem conservada, como mostra a Figura 1. A construção é um monumento histórico, construído por volta do século XVII pelos Carmelitas, com azulejos portugueses da época em sua fachada, onde recebe inúmeros fiéis todos os dias, além de turistas (Bueno, 
2016).

Figura 1: Vista da fachada da Igreja e Convento de Nossa Senhora do Carmo.

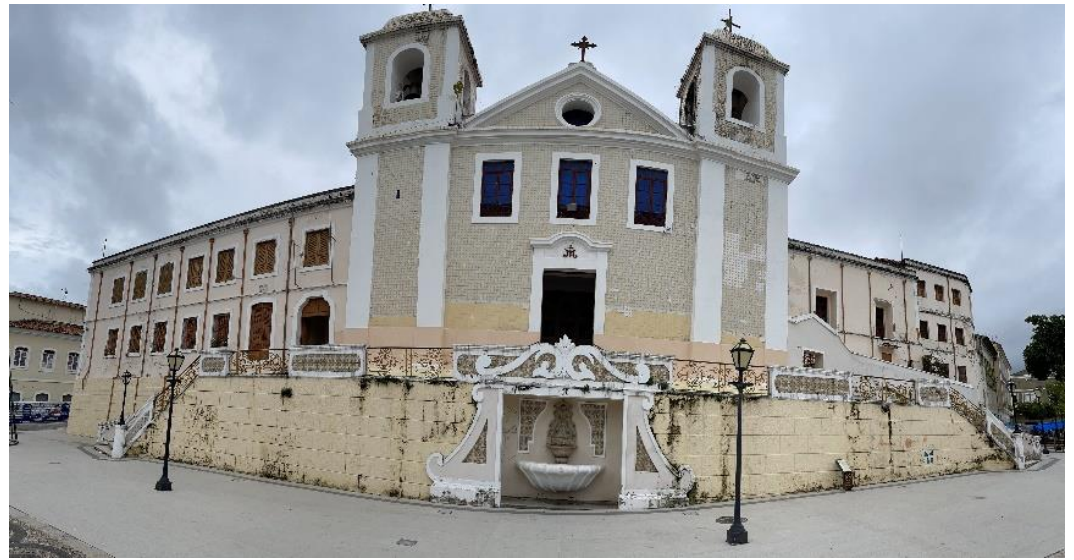

Fonte: Autores (2021).

Quando construída, em 1624, a igreja foi usada para catequizar e educar a população, logo após, em 1641, tornou-se um forte para as tropas portuguesas, enquanto os holandeses invadiam a cidade. Com isso, a Igreja de Nossa Senhora do Carmo sofreu investidas, avariando sua fachada e outras áreas do edifício (Bueno, 2016).

Ainda segundo Bueno (2016), no ano de 1808, foram realizadas enormes restaurações e construções na igreja, como as suas duas torres, além dos reparos na própria fachada da igreja. Com o passar dos anos, foram realizadas pelo menos vinte restaurações e reformas na igreja desde a sua construção. Com isso, a sua situação de preservação é considerada estável em relação aos demais edifícios históricos da região.

\section{Manifestações patológicas na construção civil}

Manifestações patológicas são problemas nas construções, seja elas prédios, casas, pontes, construções novas ou antigas. O estudo das manifestações patológicas pode ser caracterizado como o estudo dos danos, deformações e insuficiências ocorridos nas construções, que podem causar consequências desde a estética, até a segurança e conforto dos usuários da edificação. Além disso, o estudo das patologias também abrange as soluções, terapias e prevenções, ou seja, a resolução desses problemas (Nazário, 2011).

Segundo Carraro (2014), as construções estão submetidas ao desgaste do tempo e intempéries, erros de projeto e execução, empego de materiais impróprios ou de pouca qualidade, utilização inadequada da edificação, falta de manutenção, entre outros. Com isso, é de suma importância a investigação completa e correta da estrutura, além da identificação das manifestações, análise e resolução adequada das características dos problemas encontrados, como as causas, origens etc.

Segundo Cirino (2020, apud Verçoza 1991), uma avaliação integral da edificação pode ser realizada com análises básicas, como inspeções ótica e através do toque, para que se tenha a situação geral do imóvel em relação ao seu estado de conservação, além do uso de técnicas mais complexas. Ainda segundo Cirino et al. (2020, apud Oliveira 2012), essas análises servem para apontar sobre a necessidade de preservação e correção de avarias nas edificações.

Por vez, temos a impressão de que as manifestações patológicas surgem apenas depois de um certo tempo que uma construção é concluída, porém, segundo Ludovico (2016), elas abrangem também a fase de projetos, a fase de obras e como sabemos, a utilização da estrutura. Portanto, todas as fases de uma edificação são importantes, pois até erros de projetos, materiais inadequados e ou mão-de-obra desqualificada podem gerar diversos problemas patológicos no futuro.

Um dos elementos construtivos que mais sofrem com as manifestações patológicas são as fachadas dos edifícios, que 
tem papel tanto estético, quando impermeabilizante para os componentes internos da estrutura. As fachadas são importantes pois têm o papel de evitar que infiltrações de qualquer tipo adentrem nas estruturas, causando diversas patologias e problemas (Silva, 2014).

De acordo com Silva (2014), os elementos de fachadas são importantes, pois realizam uma função essencial, eles agem como um obstáculo para as cargas variadas que surgem do interior e do exterior da edificação. Essas cargas podem ser resultantes de ações climatológicas, do tempo, de origem física, mecânica ou química. Uma edificação que foi construída há muito tempo, pode sofrer bem mais com os sintomas patológicos, pois ele propicia essas manifestações.

Desta forma, é necessário compreender o funcionamento das patologias que afetam os elementos de fachada, desde a sua identificação, até a proposta de solução desses problemas, pois o tratamento correto pode evitar diversos outros problemas que podem afetar o uso e conforto de uma edificação. Além de um bom entendimento sobre as manifestações patológicas, também é necessário a correta escolha de materiais e descrição do projeto, pois dificulta o surgimento de contratempos ao longo da obra (Taguchi, 2010).

\section{Principais manifestações patológicas}

De acordo com Carasek (2010), são inúmeros os tipos de categorização das manifestações patológicas, entretanto, Helene (1992), sugere classificá-las de em quatro categorias: umidade, descolamento de revestimentos, fissuras e trincas e falhas de acabamento.

Segundo Antunes (2010), são diversas as manifestações patológicas que podem causar danos a uma edificação, porém, as mais habituais são:

Fissuras e trincas: a NBR 9575:2010/ABNT, afirma que são geradas por defeitos no procedimento de construção das edificações, no qual microfissuras contém a aberturas inferiores a $0,05 \mathrm{~mm}$, já as fissuras possuem de $0,05 \mathrm{~mm}$ a $0,5 \mathrm{~mm}$ e trincas, de 0,5 $\mathrm{mm}$ até 1,0 mm. Ioshimoto (1995), explica que essas manifestações patológicas podem aparecer devido a fatores específicos, como: tensões térmicas e higroscópicas, recalque da fundação e dilatação ou retração do revestimento. As fissuras e trincas também podem ser mapeadas ou retilíneas e apontar falhas na estrutura, por exemplo e quando presente em revestimentos cerâmicos, chama-se de gretamento.

Eflorescência e criptoeflorescência: é o acúmulo de sais minerais esbranquiçados sobre os revestimentos, porém, ocasionando apenas uma estética desagradável e geralmente nada além disso. A eflorescência pode ocorrer devido a presença de umidade no revestimento, que encontra os sais minerais (hidróxido de cálcio ou de magnésio) presentes na cal mal hidratada, podendo haver uma pressão hidrostática, fazendo com que eles aflorem sobre o revestimento, podendo se cristalizar (Peres, 2001). A umidade pode chegar até esses materiais por meio de fissuras e trincas nos revestimentos ou sob eles. Quando a eflorescência ocorre debaixo de revestimentos de pinturas, chama-se de criptoeflorescência (Bauer, 2007).

Desplacamento, descolamento ou destacamento do revestimento: é a desafixação ou caimento do revestimento em pedaços pequenos ou grandes, que podem ser provocados por baixa aderência entre o substrato e o revestimento, matéria prima imprópria, pouca resistência do revestimento aplicado, aplicação incorreta, farelos presentes entre o revestimento e a base de aplicação ou a soma destes fatores. Em revestimentos cerâmicos, pode correr também por falta do rejunte, que serve como junta de dilatação, que servem para aliviar as tensões causadas pela variação de temperatura ou outros esforços (Bauer, 2007).

Vesículas e empolamento: são erupções e bolhas causadas pela má extinção das cales antes da aplicação do revestimento. Assim como a eflorescência, a umidade atinge os óxidos de cálcio mal hidratados, que podem aumentar de volume, ocasionando também a erupção ou bolha no revestimento (Cordeiro apud Bauer, 2005).

Descamação: com o passar do tempo, a pintura tente a soltar do substrato, ocasionada pelas intempéries ou também por má aderência do revestimento de pintura. Nesse último caso, a presença de pulverulências na superfície pode causar a descamação 
da pintura (Polito, 2006).

Saponificação: é a estética rugosa da pintura, que por vez, se parece com a pele de sapos. A saponificação é provocada pela alcalinidade gerada durante a aplicação do revestimento de pintura antes dos 28 dias de cura do substrato, que pode ser argamassa ou concreto. Portanto, deve-se aguardar o tempo de cura para dificultar o surgimento dessa patologia (Santos, 2013).

Enrugamento: são rugas e sinuosidades que surgem no revestimento por excesso de demãos aplicadas de forma errada ou por aplicação em lugares em incidência solar ou calor demasiado durante a pintura (Santos, 2013).

Fungos e bolor: são colônias de fungos de cores variadas, que causam um aspecto desagradável ao revestimento. Eles surgem com temperaturas acima de $10^{\circ} \mathrm{C}$ e abaixo de $30^{\circ} \mathrm{C}$, com bastante umidade no ar e locais relativamente escuros. Também é necessário que existam nutrientes para que esses microrganismos possam se desenvolver, como solo ou fontes de poeiras. Caso esses fungos adentrem a uma camada mais profunda do revestimento, podem fazer com que ele desagregue (Guerra, 2012).

\section{Origem das manifestações patológicas}

De acordo com Roscoe (2008), o bom entendimento da origem das manifestações patológicas é de grande importância para identificar o motivo dos problemas que acometem os revestimentos. Roscoe (2008) também afirma que é possível categorizar a origem das manifestações patológicas deste modo:

Construtivas: acontecem no decorrer da obra, por mão-de-obra desqualificada e métodos construtivos inapropriados e materiais inadequados. Também são esses tipos de patologias que geralmente causam a maior parte dos problemas nas edificações.

Adquiridas: surgem no decorrer da vida útil da edificação, em consequência das intempéries e ações naturais do tempo ou por atividade humana, por falta de manutenções impróprias ou mesmo inexistentes e ou por resultado da utilização que geram as manifestações patológicas.

Congênitas: são causadas por erros de projetos, despreparo, ignorância em relação às normas técnicas ou até mesmo negligência do projetista, que consequentemente geram problemas nos detalhamentos e revestimentos da edificação. Geralmente são as que têm maior incidência de falhas que resultam em patologias.

\section{Metodologia}

Inicialmente, o estudo foi baseado na revisão bibliográfica acerca das manifestações patológicas na engenharia civil. A pesquisa foi feita em artigos científicos, monografias, teses, dissertações, artigos eletrônicos, entre diversos outros. Essa ampla pesquisa bibliográfica foi feita para que houvesse pleno entendimento sobre o tema tratado neste estudo.

O objeto do estudo de caso, a Igreja de Nossa Senhora do Carmo, foi escolhido devido a estudos científicos anteriores e devido ao grande e belo acervo histórico e cultural do Centro Histórico da cidade de São Luís - MA, que por ser uma construção antiga é, de certa forma, um monumento ideal para este trabalho.

Durante a revisão bibliográfica, foram feitas diversas visitas à Igreja de Nossa Senhora do Carmo, a fim de saber sobre a história do local e conhecer o ambiente interno e externo da igreja, além de obtenção de ficheiros eletrônicos, como plantas, arquivos de texto e de desenho técnico. Em algumas dessas visitas, foram realizadas inspeções visuais e registros fotográficos da fachada da edificação, para que pudesse analisar melhor as manifestações patológicas encontradas ali e comparar com a bibliografia estudada.

Devido à grande extensão da igreja, como mostra a Figura X, o estudo focou-se apenas em sua fachada principal, excluindo a fachada do convento. No total, a Igreja e Convento de Nossa Senhora do Carmo possuem uma extensão de 73,96 metros de comprimento apenas de frontaria.

Para adaptação das plantas, foi utilizado o programa Autocad 2022, software de desenho técnico, para evidenciar a área do estudo. A região estudada é a igreja no centro do quadrado amarelo na Figura 2, que alcança 18,73 metros de comprimento e 
20,58 metros de altura.

Figura 2: Fachada da Igreja e Convento de Nossa Senhora do Carmo.

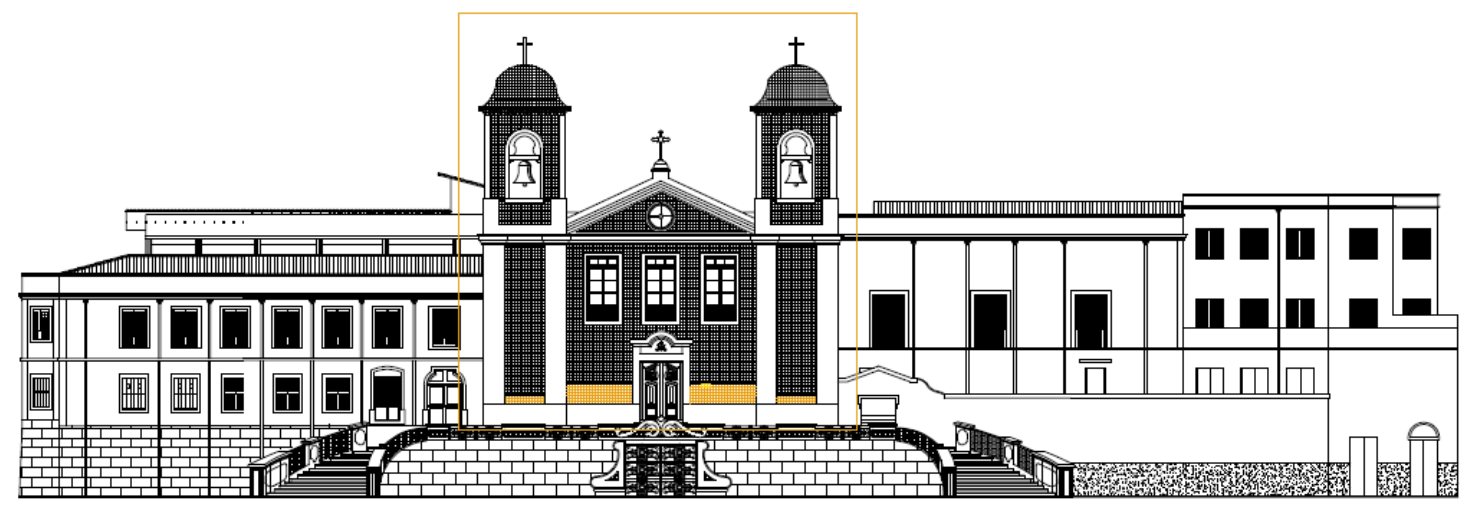

Fonte: Adaptado de Fonseca (2014).

Mesmo com a delimitação apresentada acima, a extensão da Igreja de Nossa Senhora do Carmo ainda é grande, então, para simplificar e melhorar o entendimento, dividiu-se a igreja em regiões onde se concentram as patologias, como mostra o exemplo da Figura 3 abaixo.

Figura 3: Fachada principal da Igreja de Nossa Senhora do Carmo.

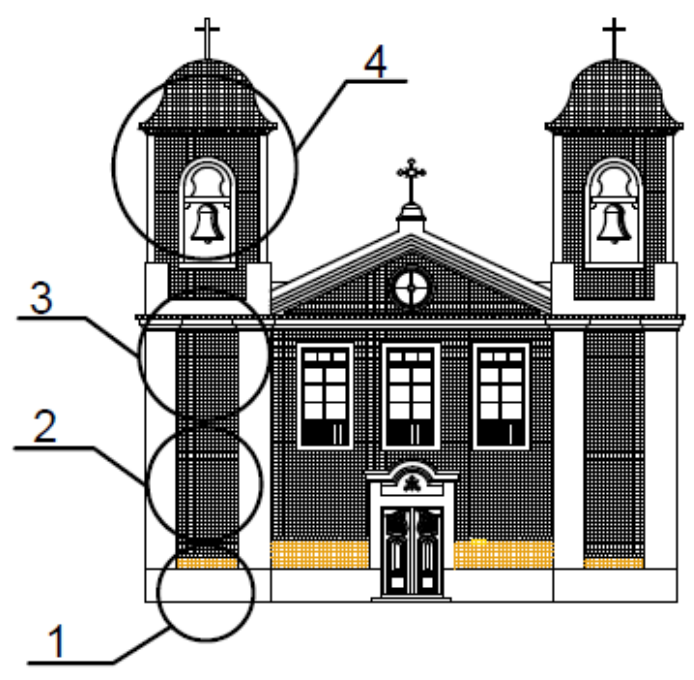

Fonte: Adaptado de Fonseca (2014).

Como mostrado na Figura 3 acima, cada região possui uma identificação numérica para facilitar a identificação das manifestações patológicas que se encontram em cada região.

\section{Resultados e Discussão}

Nas visitas à edificação, pôde-se ver que a fachada da igreja estava relativamente bem preservada, porém, se forem observados os detalhes de perto, nota-se alguns pequenos focos de manifestações patológicas em determinadas áreas da fachada da igreja.

Os procedimentos de restauro necessitam obedecer às características originárias da edificação histórica, mantendo suas particularidades históricas. As chamadas Cartas de Restauro devem ser seguidas à risca, pois são elas que normatizam as técnicas 
de restauro e preservação dos imóveis que compões patrimônio histórico (Klüppel, 2005).

Como muitas regiões possuem as mesmas manifestações patológicas, foi possível elaborar um quadro contendo um resumo para facilitar o entendimento e a amostragem de dados. A Tabela 1 abaixo, é a relação de manifestações patológicas por região, além das possíveis causas e o tratamento recomendado para cada região.

Tabela 1: Relação de manifestações patológicas por região, causas e terapias.

\begin{tabular}{|c|c|c|c|}
\hline Regiões & Manifestações identificadas & Possíveis causas & Terapia recomendada \\
\hline $\begin{array}{l}2,3,7,8,9,10 \\
12\end{array}$ & $\begin{array}{l}\text { Gretamento, fissuras e trincas, } \\
\text { deslocamento, deterioração das } \\
\text { juntas. }\end{array}$ & $\begin{array}{l}\text { Intemperismo, que gera umidade, que pode causar } \\
\text { tensões de tração, no caso do gretamento. No caso } \\
\text { das fissuras, podem ser causadas por variações de } \\
\text { temperatura e ausência ou uso incorreto de juntas } \\
\text { de dilatação. Já para o deslocamento, é a perca } \\
\text { natural de aderência entre o revestimento e a massa } \\
\text { colante/substrato. }\end{array}$ & $\begin{array}{l}\text { Para o gretamento, fissuras e trincas do } \\
\text { revestimento cerâmico, deve haver uma } \\
\text { equipe especializada para o reparo, sem } \\
\text { descaracterizar a peça. }\end{array}$ \\
\hline 1 & Infiltração. & $\begin{array}{l}\text { Água da chuva que pode adentrar e se acumular } \\
\text { através de fissuras e deterioração das juntas no } \\
\text { revestimento cerâmico que se encontra acima ou } \\
\text { oriunda da área interna da edificação. }\end{array}$ & $\begin{array}{l}\text { Nesse caso, deve haver o tratamento das } \\
\text { peças cerâmicas que se encontram acima, } \\
\text { para evitar o acúmulo de umidade no } \\
\text { revestimento abaixo. }\end{array}$ \\
\hline 4,13 & $\begin{array}{l}\text { Destacamento do revestimento } \\
\text { cerâmico, gretamento. }\end{array}$ & $\begin{array}{c}\text { Perca da aderência do revestimento à base, } \\
\text { movimentações cíclicas da estrutura, levando a } \\
\text { queda de algumas placas do revestimento. }\end{array}$ & $\begin{array}{l}\text { Remoção com cuidado das peças que não } \\
\text { estejam fissuradas ou com gretamento, } \\
\text { limpeza da área e recolocação das peças com } \\
\text { argamassa própria e rejuntamento após } 1 \\
\text { semana. }\end{array}$ \\
\hline 5,6 & Encardimento da superfície. & $\begin{array}{l}\text { Sujeira trazida pelos ventos e chuvas e por pessoas } \\
\text { que passam pelo local. }\end{array}$ & $\begin{array}{l}\text { Lavar com bastante água e uso de produtos } \\
\text { químicos adequados, escovação da área. Em } \\
\text { casos extremos, deve-se lixar, remover as } \\
\text { pulverulências e reaplicar o revestimento de } \\
\text { pintura. }\end{array}$ \\
\hline 11 & $\begin{array}{l}\text { Descolamento de pintura, } \\
\text { empolamento e fissuras. }\end{array}$ & $\begin{array}{l}\text { Descolamento possivelmente causado por } \\
\text { aplicação de pintura em base húmida ou } \\
\text { pulverulenta. No caso das bolhas, podem ser } \\
\text { causadas por má hidratação das cales antes da } \\
\text { aplicação do revestimento. No caso das fissuras, } \\
\text { provavelmente causadas por cargas excessivas ou } \\
\text { variações de temperatura. }\end{array}$ & $\begin{array}{l}\text { Para o descolamento, deve-se remover a parte } \\
\text { da pintura que esteja solta ou fofa, usar lixa e } \\
\text { limpar, após, usar tintas adequadas. Para as } \\
\text { fissuras e trincas que não atinjam a estrutura, } \\
\text { deve-se usar argamassa para tapar as fissuras. } \\
\text { Para o empolamento, deve-se remover a área } \\
\text { afetada, limpar a região com escova e } \\
\text { reaplicar o revestimento. }\end{array}$ \\
\hline
\end{tabular}

Fonte: Autores (2021).

Abaixo, as imagens, para ilustrar o Quadro 1, de algumas áreas da fachada da Igreja de Nossa Senhora do Carmo onde se encontram os focos de manifestações patológicas, levando em consideração que algumas regiões possuem as mesmas patologias.

Na Figura 5 da região 6, pode-se ver algumas machas na pintura, o que configura o seu encardimento. Muitas dessas marcas parecem ser de mãos de pessoas que passam pela igreja e outras, manchas de poeira, provavelmente provenientes da chuva e ventos. 
Research, Society and Development, v. 11, n. 2, e24011225819, 2022

(CC BY 4.0) | ISSN 2525-3409 | DOI: http://dx.doi.org/10.33448/rsd-v11i2.25819

Figura 5: Imagem da região 6.

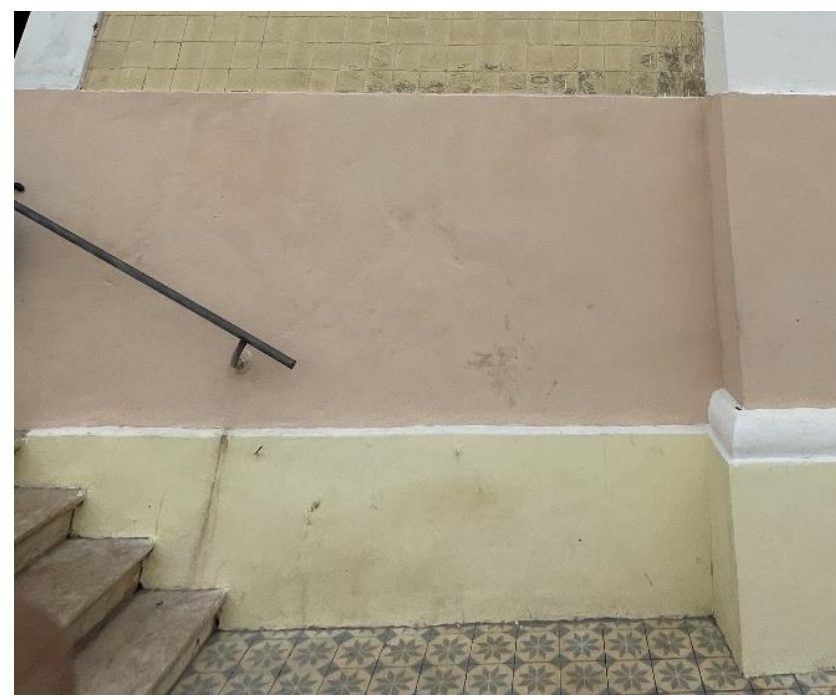

Fonte: Autores (2021).

Na Figura 6 da região 11, pode-se ver alguns empolamentos e pequenas fissuras. Nota-se essas patologias não foram tratadas antes que fosse colocado o revestimento de pintura por cima.

Figura 6: Imagem da região 6.

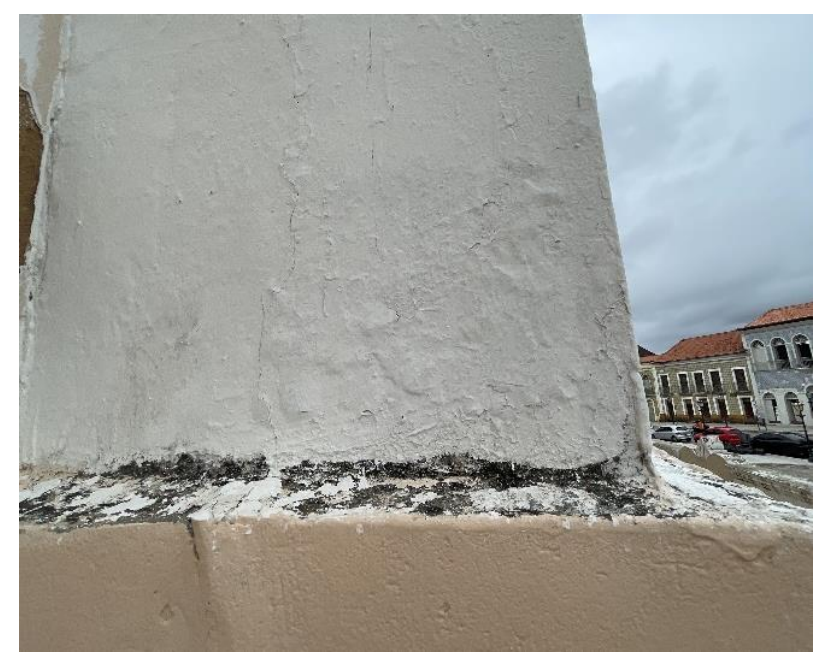

Fonte: Autores (2021).

Ainda na região 11, em outra face de seu pilar, como mostra a Figura 7, pode-se observar o descolamento do revestimento de pintura. 
Research, Society and Development, v. 11, n. 2, e24011225819, 2022

(CC BY 4.0) | ISSN 2525-3409 | DOI: http://dx.doi.org/10.33448/rsd-v11i2.25819

Figura 7: Imagem da região 11.

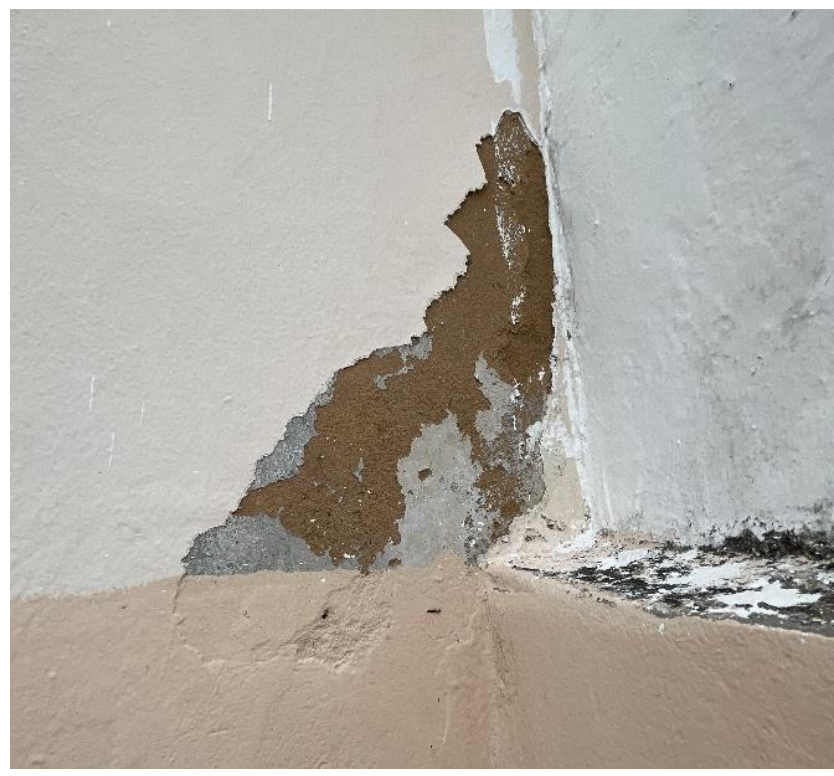

Fonte: Autores (2021).

Na Figura 8 da região 7, pode-se observar fissuras e gretamento no revestimento cerâmico, além das juntas parcialmente deterioradas.

Figura 8: Imagem da região 7.

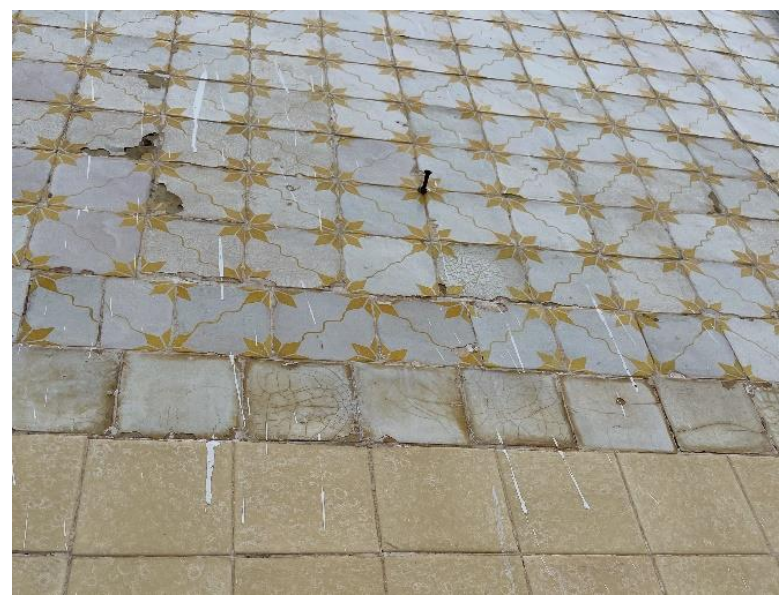

Fonte: Autores (2021).

Na Figura 9 da região 12, além dos problemas encontrados também na região 7, pode-se notar o deslocamento do revestimento cerâmicos, já que algumas peças parecem estar fofas e se sobressaem em relação às demais. 
Research, Society and Development, v. 11, n. 2, e24011225819, 2022

(CC BY 4.0) | ISSN 2525-3409 | DOI: http://dx.doi.org/10.33448/rsd-v11i2.25819

Figura 9: Imagem da região 12.

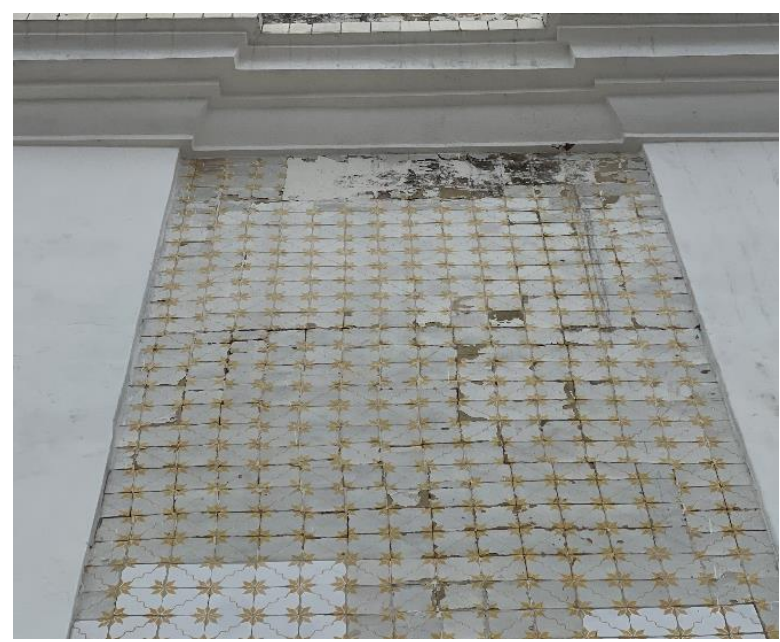

Fonte: Autores (2021)

Na Figura 10, da região 13, onde encontra-se a cúpula que abriga o sino da igreja, pode-se notar o destacamento próximos aos beirais inferior e superior, além do gretamento do revestimento cerâmico.

Figura 10: Imagem da região 13.

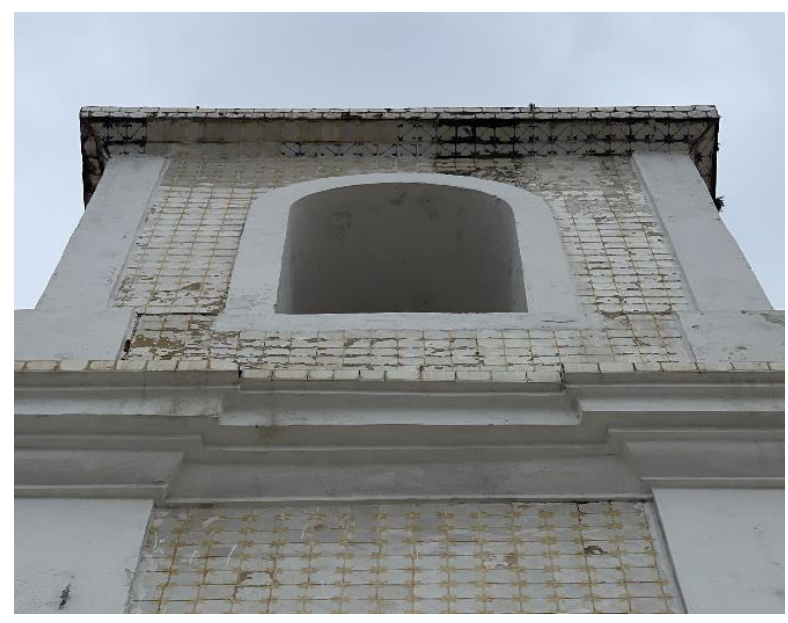

Fonte: Autores (2021)

Por fim, na Figura 11 da região 1, pode-se notar machas de umidade, que pode significar uma infiltração. 
Figura 11: Imagem da região 1.

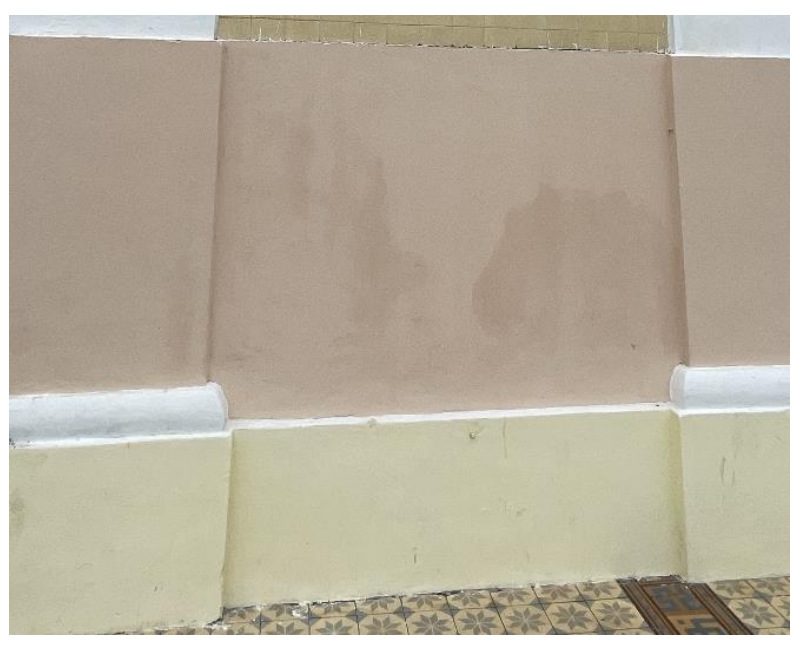

Fonte: Autores (2021)

\section{Considerações Finais}

Pôde-se perceber através deste trabalho, que as condições da fachada da Igreja de Nossa Senhora do Carmo são relativamente satisfatórias, pois, visto que se trata de um imóvel que foi construído há séculos e sofreu por diversos problemas como combates durante a invasão a cidade dos holandeses, intempéries e o envelhecimento natural, é espontâneo pensar que a fachada da igreja estivesse em condições não aceitáveis.

No entanto, ainda assim, as manifestações patológicas são fáceis de serem encontradas na fachada da igreja, como fissuras, descolamento de pintura, empolamentos do revestimento argamassado e gretamento do revestimento cerâmico, que é o mais comum, já que a maior parte da fachada é revestida por ele. Com isso, é necessário a intervenção apropriada nesse tipo de revestimento, baseadas nas soluções propostas, pois são peças de arquitetura portuguesas, com valor histórico e cultural inestimáveis e por isso, não devem se degradar com o passar do tempo.

Dessa forma, pode-se ver, através deste estudo, que se obteve resultados consideráveis e que podem servir para futuros trabalhos e pesquisas científicas que envolvam edifícios históricos, como restaurações de revestimentos em fachadas construções históricas ou até mesmo estudos similares a este em outras regiões que contenham imóveis históricos.

\section{Referências}

ABNT - Associação Brasileira de Normas Técnicas. (2010). NBR 9575: Impermeabilização - Seleção e projeto. Rio de Janeiro.

Antunes, G. R. (2010). Estudo das Manifestações Patológicas em Revestimentos de Fachada em Brasília - Sistematização da Incidência de Casos. Dissertação de Mestrado - Universidade de Brasília. Faculdade de Tecnologia.

Barbosa, M. T. G.; Polisseni, A. E.; Tavares, F. M. (2010). Análise e representação em contextos diversos: projeto, técnica e gestão do ambiente construído. I ENANPARQ, Rio de Janeiro. http://www.anparq.org.br/dvd-enanparq/simposios/173/173-737-1-SP.pdf

Bauer, L. A. F. (2007). Materiais de Construção. 5.ed. Rio de Janeiro: Livros Técnicos e Científicos. Editora. Volume 1.

Bueno, B.I. (2016). Monumentos Históricos do Maranhão: revisão e atualização. São Luís.

Carasek, H. (2010). Argamassas. In: Materiais de Construção Civil e Princípios de Ciência e Engenharia de Materiais. ISAIA, G. C. (Organizador/editor). São Paulo: IBRACON.

Carraro, C. L.; \& Dias, J. F. (2014). Diretrizes para prevenção de manifestações patológicas em Habitações de Interesse Social. FapUNIFESP (SciELO). [s.1.], v. 14, n. 2 , p. $125-139$.

Cirino, M. A. G; Oliveira, B. B.; Pereira, S. L. O.; Cordeiro, S. B.; Morais, J. M. P.; Silva, E. M.; \& Barboza, E. N. (2020). Avaliação das manifestações patológicas das edificações do departamento de engenharia de alimentos da Universidade Federal do Ceará. Research, Society and Development, 9(7):1-21, e481974424. https://rsdjournal.org/index.php/rsd/article/view/4424/3659 
Research, Society and Development, v. 11, n. 2, e24011225819, 2022

(CC BY 4.0) | ISSN 2525-3409 | DOI: http://dx.doi.org/10.33448/rsd-v11i2.25819

Cordeiro, J. T. de L.; Barbosa, V. M.; \& Vilas Boas, D. C. C. (2021). Levantamento das manifestações patológicas da construção civil: um estudo em residência domiciliar na Cidade de São Luís, Maranhão. Research, Society and Development, [S. 1.], v. 10, n. 12, p. e184101220487 10.33448/rsd-v10i12.20487. https://rsdjournal.org/index.php/rsd/article/view/20487

Corrêa, A. F. (2001). Vilas, parques, bairros e terreiros: novos patrimônios na cena das políticas culturais em São Paulo e São Luís. São Paulo: s.n.

Ferreira; A. R.; \& Oliveira, R. F. (2021). Patologias na construção civil: estudo de caso em duas residenciais na cidade de Iraí de Minas - MG. Revista GETEC, Monte Carmelo, v. 10, n. 26, p. 1-16.

Fonseca, H. (2014). Planta de Fachada Leste da Igreja de Nossa Senhora do Carmo. In: Iphan, Ficheiro DWG 3.97 Mb.

Guerra, F. L. (s. d.). Bolor nas paredes pode causar danos às estruturas das edificações. In: Portal AecWeb. https://www.aecweb.com.br/cont/m/rev/bolor-nasparedespode-causar-danos-as-estruturas-das-edificacoes/7490

Helene, P. R. L. (1992). Manual Para Reparo, Reforço e Proteção de Estruturas de Concreto. 2. ed. São Paulo: Pini.

Ioshimoto, E. (1995). Incidência de manifestações patológicas em edificações habitacionais. In: Instituto de Pesquisas Tecnológicas (IOT). Tecnologia de Edificações. 2. Ed. São Paulo: Pini.

IPHAN - Instituto do Patrimônio Histórico e Artístico. (s. d.). Centro Histórico de São Luís (MA). http://portal.iphan.gov.br/pagina/detalhes/34

Klüppel, G. P.; \& Santana, M. C. de. (2005). Manual de Conservação Preventiva para Edificações. Brasília: Programa Monumenta/IPHAN.

Lersch, I. M. (2003). Contribuição para a identificação dos principais fatores de degradação em edificações do patrimônio cultural de Porto Alegre. Dissertação de Mestrado. Programa de Pós-Graduação em Engenharia Civil, Universidade Federal do Rio Grande do Sul, Porto Alegre.

Luduvico, T. S. (2016). Desempenho a estanqueidade à água: interface janela e parede. Dissertação de Mestrado, Universidade Federal de Santa Maria, Santa Maria, 2016. https://repositorio.ufsm.br/handle/1/7928

Nazario, D.; \& Zancan, E. C. (2011). Manifestações das patologias construtivas nas edificações públicas da rede municipal e Criciúma: Inspeção dos sete postos de saúde. Santa Catarina.

Peres, R. M. (2001). Levantamento e identificação de manifestações patológicas em prédio histórico - estudo de caso. Dissertação (Mestrado em Engenharia Civil). Universidade Federal do Rio Grande do Sul, Rio Grande do Sul.

Polito, G. (2006). Principais sistemas de pinturas e suas patologias. Dissertação de Pós-Graduação em Engenharia Civil. Universidade Federal de Minas Gerais, Minas Gerais.

Roscoe, M.T. (2008). Patologias em revestimento cerâmico de fachada. Dissertação de Pós-Graduação em Engenharia Civil. Universidade Federal de Minas Gerais, Minas Gerais, 2008.

Santos, S. S. dos. (2013). Patologia das construções. Artigo técnico. Curitiba: IPOG - Instituto de Pós-Graduação e Graduação. 14 p.

Silva, M. N. B. (2014). Avaliação Quantitativa da Degradação e Vida Útil de Revestimentos de Fachada-Aplicação ao Caso de Brasília/DF. Tese de Doutorado em Estruturas e Construção Civil, Publicação E.TD-006A/14, Departamento de Engenharia Civil e Ambiental, Universidade de Brasília, Brasília, DF, 198 p.

Taguchi, M. K. (2010). Avaliação e qualificação das patologias das alvenarias de vedação nas edificações. 64 f. Dissertação (Mestrado) - Curso de Engenharia Civil, Setor de Tecnologia da Universidade Federal do Paraná, Universidade Federal do Paraná, Curitiba.

Tavares, F. M. (2011). Metodologia de diagnóstico para restauração de edifícios dos séculos XVIII e XIX nas primeiras zonas de mineração em Minas Gerais. Dissertação (Mestrado em Ambiente Construído) Faculdade de Engenharia, Universidade Federal de Juiz de Fora, Minas gerais. 